\title{
STAND DENSITY VS. STAND BOLE AREA AND STAND INTENSITY INDICES IN EVEN-AGED STANDS
}

\author{
By G. A. Mulloy \\ Dominion Forest Service
}

$T^{N}$ N THE Joumal of Forestry, December, 1943, Mr. Bert Lexen has an article entitled, "Bole Area as an Expression of Growing Stock" in which he develops the concept that the index of growth power is the total area of cambium layer in all trees on an acre of forest. The remarkable thing, however, is that, in developing a formula for its use, he found that the average diameter in inches multiplied by the average height in feet and by the number of trees per acre and then divided by a constant gave a good measure of the total stand bole area in square feet. This means that diameter $X$ height $X$ number of trees can be used as an index of stocking, since it does not matter what constant is used as a divisor.

In a large number of red and white pine plots at the Petawawa Forest Experiment Station this index (called S.B.I.) was calculated by multiplying D, H, and N. With the same plot data the S.D.I. had been already calculated. This latter is Reineke's index, in which the number of trees is plotted over the average diameter and the S.D.I. read from a double-log graph. These two indices may be compared. First, however, it was necessary to bring the S.B.I. and the S.D.I. to a similar basis of comparison.

Thus, in a plot with 579 trees, average diameter 6.0 inches and height 60 feet, the quotient would be 208,400 , while the S.D.I. of the plot is only 265 . To bring these two measures of density to a comparable basis it would be necessary to reduce the larger number. This was done by adding all the S.D.I's and S.B.I.'s and finding the relation of these totals. It was found that by dividing the larger number by a constant of 659 the totals would be the same. If the decimal point; be neglected this is very close to the divisor used by Lexen who uses 6.6 for mature Ponderosa stands.

To investigate the correlation, the two indices of all measurements have been plotted on regular cross-section paper in which the scale is the same vertically and horizontally (Fig. 1). If the indices are exactly the same, the average line through the points representing pairs of values for each plot should run at a 45 -degree angle ${ }^{1}$. The averages show that the line is curvilinear; a very shallow curve being shown. This means that the introduction of height into the index affects it to some extent, the greater effect being in the low densities between 150-250. However, the average points (totalling 144 out of 150 ) are very close to the 45 -degree line.

It is concluded, therefore, that whether S.D.I. or S.B.I. is used as an index, for all practical purposes they provide the same relative measure of density index.

1. Forest Mensuration: Bruce and Schumaker, pp. 257 


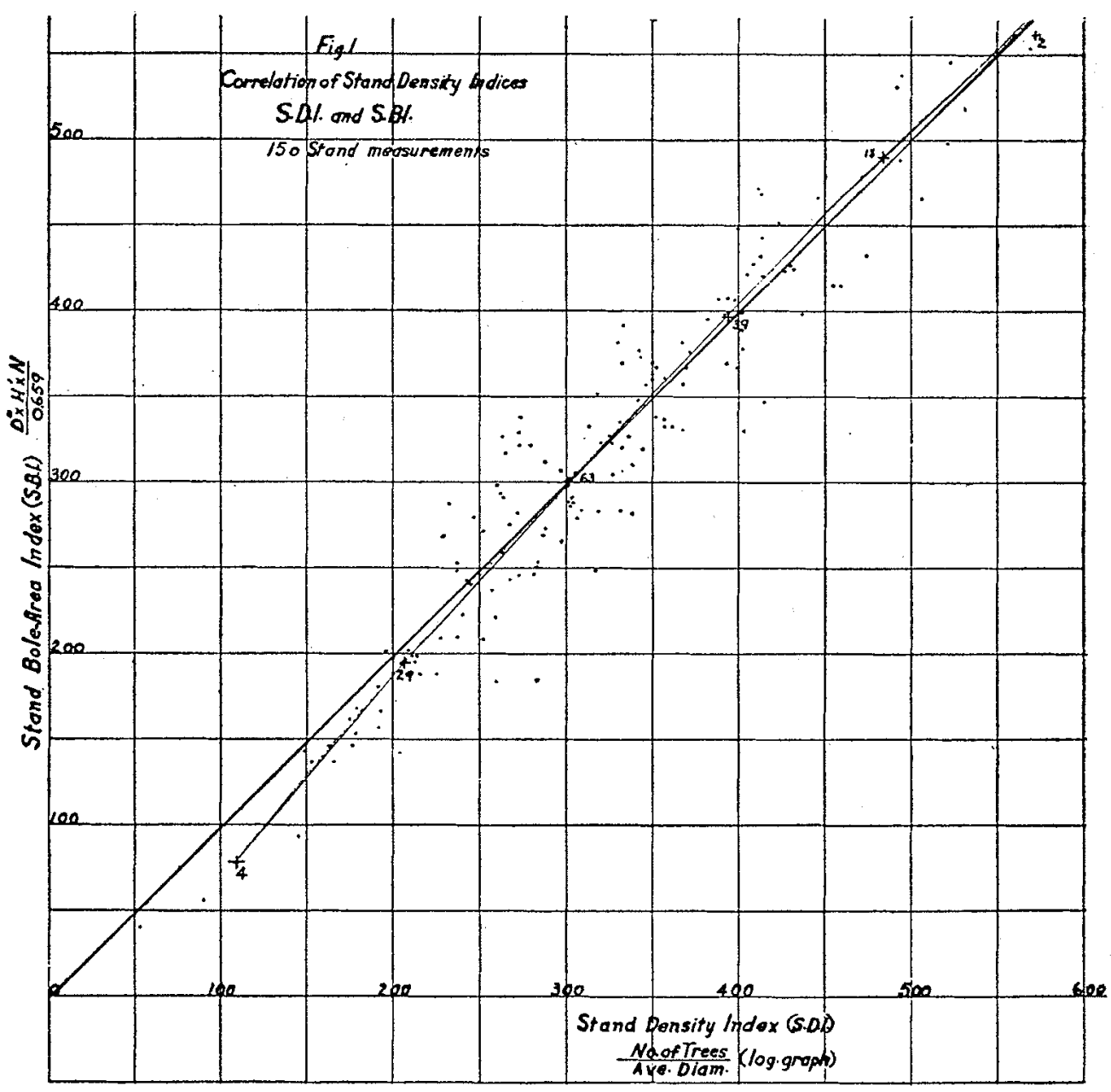

There is another measure of stand density which has been used. It is called the Stand Intensity Index and is obtained by dividing the total volume in cubic feet by the height: this had been calculated for the same plots. It may also be compared with the S.D.I. (Reineke) in the same manner. The comparison is shown in Figure 2. It is apparent that while correlation is strong, it is not only curvilinear but deviates quite markedly from the 45 . degree slope in the upper densities. Two measurement points will be noted 


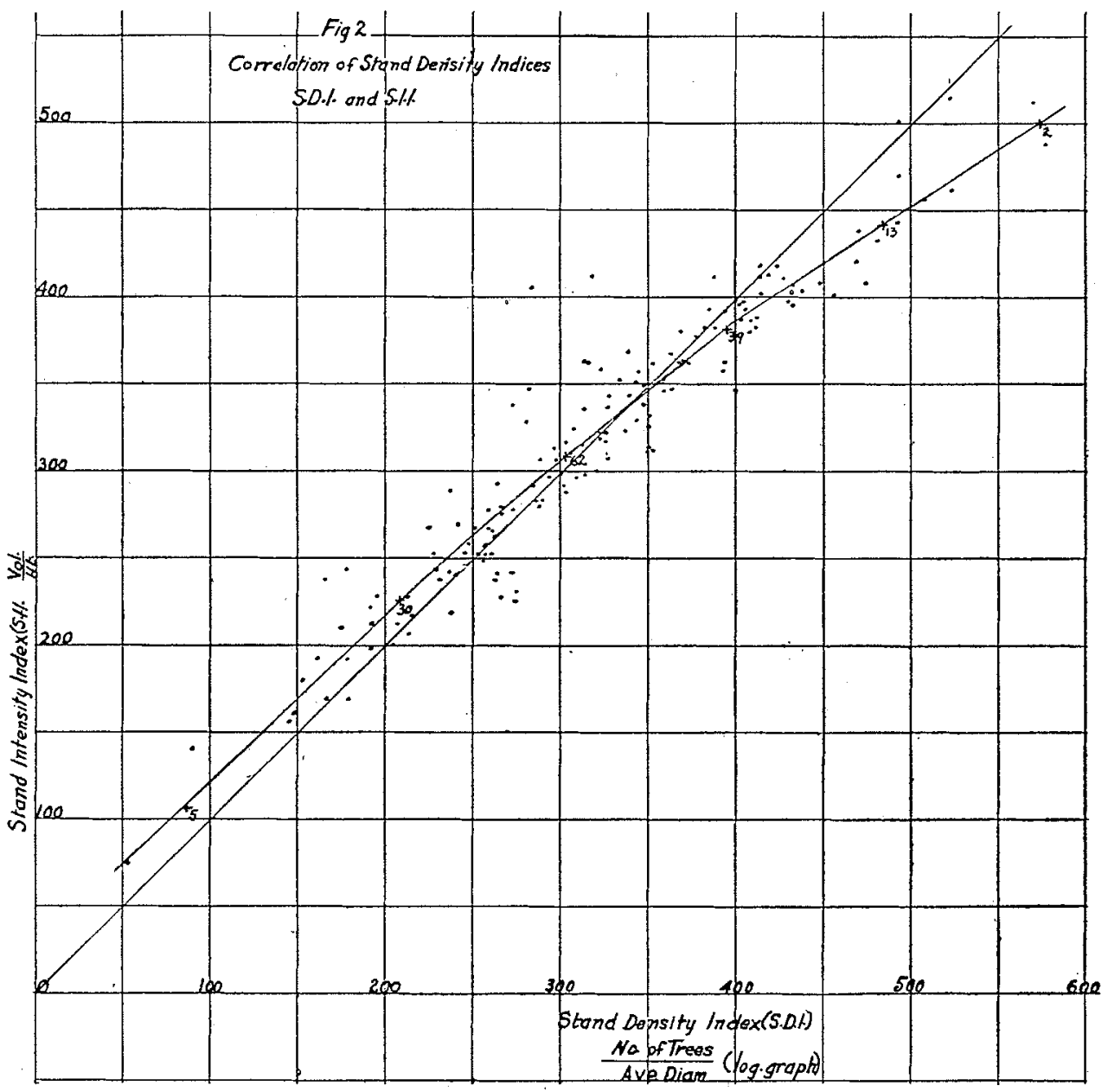

much above all others, near the 300 S.D.I. and 400 S.I.I. These are the original measurements before thinning for plots in which two ages were represented, poplar, 75 years, and pine, 35 years. The poplar was removed, and at the next remeasurement the plotted point fell close to the 45 -degree line. This shows that such two-aged stands in such a system of measuring density must be treated as belonging to one or other of the age-groups, and only that age-class considered in calculating density. 
In such comparisons, of course, good correlation would be expected because of the four parameters: diameter, height, number of trees and volume; two or more are used in each of the three measures of density. These comparisons do seem to show that either the Stand Bole Area Index or the Stand Intensity Index can be used instead of the Stand Density Index (Reineke's) without much inconsistency. They are all consistent in their relative measure of stand density.

Any reasonable accurate measure of stand density is better than none at all, and these three seem to offer a good choice. In some ways the stand bole area index (S.B.I.) seems to have certain advantages since it uses the three most easily obtained factors of diameter, height and number of trees. How. ever, its use as yet has not been proved in practice as has stand density index (S.D.I.) which uses the two parameters, number of trees, and average diameter, but uses a log graph or table to read indices. 